\title{
Antalya Eğitim ve Araştırma Hastanesi multipl skleroz polikliniğinin oral tedavi deneyimi
}

\author{
Oral treatment experience in multiple sclerosis at Antalya Training and Research Hospital
}

\author{
Burcu Yüksel, Fatma Kurtuluş, Abidin Erdal
}

Gönderilme tarihi: 21.12. 2018

Kabul tarihi: 01.02.2019

\section{Özet}

Amaç: Bu çalışmanın amacı Sağlık Bilimleri Üniversitesi Antalya Eğitim ve Araştırma Hastanesi multipl skleroz (MS) polikliniğinin oral tedavi deneyimini paylaşmak, hastalar için uygun tedaviyi seçmenin önemini vurgulamaktır.

Gereç ve Yöntem: 2012-2018 yılları arasında MS polikliniğinde en az 6 aydır düzenli takip edilen 550 hastanın dosyası retrospektif olarak incelendi. Demografik veriler, daha öncesinde kullanmakta olduğu tedaviler ve hangi sebeple (relaps sıklığında artış, progresyon, MR aktivasyonu, hasta isteği, önceki ilaca bağlı yan etki) oral tedavi tercih edildiği, hastalık süreleri ve ne kadar süredir oral tedavi kullanmakta oldukları, hastalık dizabilitesini ölçen Expanded Disability Status Scale (EDSS) skorları kaydedildi.

Bulgular: 2010 McDonald kriterlerine göre kesin MS tanısı alan 550 hasta çalışmaya dahil edildi. 108 $(\% 19,6)$ hasta oral tedavilerden (fingolimod, dimetilfumarat ya da teriflunomid) birini kullanmaktaydı. 53 hasta $(\% 49,1)$ fingolimod, 34 hasta $(\% 31,5)$ dimetilfumarat, 21 hasta $(\% 19,4)$ teriflunomid kullanmaktaydı. En fazla atak sıklığında artış nedeniyle oral tedavi tercih edildiği saptandı.

Sonuç: Oral tedavi kulanım oranımız Türkiye ortalamasının altında olsa da bulgularımız, tedavi değişimi yaptığımızda tedavi penceresi içinde kaldığımızı göstermektedir.

Anahtar Kelimeler: Multipl skleroz, oral tedavi, fingolimod, dimetilfumarat, teriflunomid.

Yüksel B, Kurtuluş F, Erdal A. Antalya Eğitim ve Araştırma Hastanesi multipl skleroz polikliniğinin oral tedavi deneyimi. Pam Tıp Derg 2019;12:281-287.

\begin{abstract}
Purpose: Our aim was to share our oral treatment experience in multiple sclerosis and how we decided to choose the right treatment for our patients.

Materials and Methods: We analyzed multiple sclerosis patients who were admitted to neurology clinic between 2012-2018. Demographic features, treatments that were used before initiating oral therapies, in which conditions the treatments were changed to oral therapies (increased relaps rate, progression, activation on magnetic resonance imaging, patient's choice, adverse events with the previous treatment), the duration of the disease and the oral treatment, Expanded Disability Status Scale (EDSS) scores were all recorded.

Results: 550 patients with a definite clinical diagnosis of MS according to the 2010 McDonald criteria were enrolled. $108(19,6 \%)$ patients were receiving oral treatment for multiple sclerosis. 53 patients $(49,1 \%)$ were receiving fingolimod, 34 patients $(31,5 \%)$ were receiving dimethylfumarate, 21 patients $(19,4 \%)$, were receiving teriflunomide. The most evident cause for changing the treatment was the increased relaps rate.

Conclusion: Although the ratio $(19,6 \%)$ seemed to be lower than the ratio from whole Turkey $(41 \%)$, the timing of the treatment change have been shown to be in therapeutic window.
\end{abstract}

Key Words: Multiple sclerosis, oral treatment, fingolimod, dimethylfumarate, teriflunomide.

Yüksel B, Kurtuluş F, Erdal A. Oral treatment experience in multiple sclerosis at Antalya Training and Research Hospital. Pam Med J 2019;12:281-287.

Burcu Yüksel, Uz. Dr. Sağlık Bilimleri Üniversitesi Antalya Eğitim ve Araştırma Hastanesi Nöroloji Kliniği, ANTALYA, e-posta: dr.burcuy@hotmail. com, (orcid.org/0000-0003-3976-5564) (Sorumlu yazar)

Fatma Kurtuluş, Doç. Dr. Sağlık Bilimleri Üniversitesi Antalya Eğitim ve Araştırma Hastanesi Nöroloji Kliniği, ANTALYA, e-posta: fatma72kurtulus@ yahoo.com, (orcid.org/0000-0002-8772-6087)

Abidin Erdal, Uzm. Dr. Sağlık Bilimleri Üniversitesi Antalya Eğitim ve Araştırma Hastanesi Nöroloji Kliniği, ANTALYA, e-posta: abidinerdal@ gmail.com, (orcid.org/0000-0003-3698-8201) 


\section{Giriş}

Multipl skleroz (MS) merkezi sinir sisteminin enflamasyon, demiyelinizasyon ve akson kaybı ile karakterize kronik otoimmün, nörodejeneratif bir hastalığıdır. Genetik ve çevresel faktörlerin de MS başlangıcını, MS'in klinik ekspresyonunu ve tedaviye cevaplılığı etkilediği düşünülmektedir [1]. Gelişmiş ülkelerde genç erişkinleri etkileyen en sık özürlülüğe yol açan hastalıktır. Günümüzde kullanılan hastalık modifiye edici tedavilerin (HMT) MS'in en sık görülen formu olan relapsing remitting MS (RRMS) için etkinliği kanıtlanmış olup klinik ve subklinik olarak hastalık aktivitesini kontrol etmek için erken tedaviye başlanması önerilmektedir. Bu tedavilerin progresif MS'te etkisi gösterilememekle birlikte son yıllarda kullanıma giren intravenöz olarak kullanılan ocrelizumabın relapsing formlar ile birlikte primer progresif MS'te de progresyonu yavaşlattığı gösterilmiştir [2, 3]. Özellikle natalizumab kullanımı ile karşımıza çıkan tedavi ile ilişkili progresif multifokal lökoensefalopati (PML) gibi hayatı tehdit edebilecek yeni riskler yeni tedavilere başlamadan önce hastaların olası riskler açısından daha ayrıntılı incelenmesi ve tedaviye başlandıktan sonra daha yakından izlenmesi gerekliliğini ortaya çıkarmıştır [4-7].

$\mathrm{Bu}$ nedenle risk yarar durumunu gözeterek hastanın klinik bulgularına, daha önce hangi tedavileri kullanmış olduğuna, hangi yan etkilerin gözlendiğine, hasta ile hekimin tedavi konusunda ortak kararına göre hastaya uygun tedavi seçilmelidir. Ek olarak tedaviye yanıtı gösteren kılavuz bir belirteç olmadığından birçok çalışma grubu hastaya göre en uygun HMT'yi tespit etmek için birçok algoritma geliştirmişlerdir. Bu algoritmaların amacı tedaviye cevabı erkenden ölçerek, zamanında tedavi değişimini (switching ya da eskalasyon) sağlayabilmektir $[8,9]$.

1990'larda kullanıma giren enjektabl HMT'lerden sonra dünyada 2010'larda kullanılmaya başlanan oral HMT'ler (fingolimod, dimetilfumarat ve teriflunomid) umut vaat edici olmuştur. Bütün bu tedavilerde son hedef klinik olarak (relaps ya da progresyon olmaması) ya da magnetik rezonans (MR) parametrelerinde (yeni T2 lezyonu ya da atrofi olmaması) ve hastalık aktivitesine yönelik kanıtın olmamasını (No Evidence of Disease Activity-NEDA) sağlamaktır [10].
$\mathrm{Bu}$ çalışmanın amacı, MS polikliniğinde düzenli takip olan RRMS hastalarına başlanan oral tedavi deneyimimizi paylaşmaktır.

\section{Gereç ve yöntem}

Sağlık Bilimleri Üniversitesi Antalya Eğitim ve Araştırma Hastanesi Nöroloji Kliniği Multipl Skleroz Polikliniği'nde 2012-2018 yılları arasında en az 6 aydır düzenli takip edilen 550 hastanın dosyası geriye dönük olarak incelendi. Demografik veriler, daha öncesinde kullanmakta olduğu tedaviler ve hangi sebeple (relaps sıklığında artış, progresyon, MR aktivasyonu, hasta isteği, önceki ilaca bağlı yan etki) oral tedavi tercih edildiği, hastalık süreleri ve ne kadar süredir oral tedavi kullanmakta oldukları, hastalık dizabilitesini ölçen Expanded Disability Status Scale (EDSS) skorları kaydedildi. Tanımlayıcı istatistik yapıldı. Özet istatistikleri ortalama \pm standart sapma olarak ifade edildi. $p<0,05$ değerleri istatistiksel olarak anlamlı kabul edildi. Tüm istatistiksel analizler Statistical Package for the Social Sciences (SPSS) v20 programı kullanılarak yapıldı.

\section{Bulgular}

2010 McDonald kriterlerine göre kesin MS tanısı alan hastalar dahil edildi. 550 hasta içinde $108(\% 19,6)$ hasta oral tedavi kullanmaktaydı (Şekil 1). 39'u $(\% 36,1)$ erkek, 69'u $(\% 63,9)$ kadındı. Ortalama hastalık süresi $10,21 \pm 7,16$ yıldı. Ortalama EDSS $2,44 \pm 1,25$ idi. Ortalama

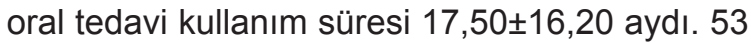
hasta (\%49,1), 32'si kadın $(\% 60,4)$ ve 21 'i erkek $(\% 39,6)$ fingolimod, 34 hasta $(\% 31,5), 21 ' i$ kadın $(\% 61,8)$ ve 13 'ü erkek $(\% 38,2)$ dimetilfumarat, 21 hasta $(\% 19,4), 16$ 'sı kadın $(\% 76,2)$ ve 5 'i erkek $(\% 23,8)$ teriflunomid kullanmaktaydı. 40 hastada (\%37) atak sıklığında artış nedeniyle, $29(\% 26,9)$ hastada klinik progresyon nedeniyle, 17 hastada $(\% 15,7)$ enjeksiyonlardan dolayı yan etki nedeniyle, 16 hastada $(\% 14,8)$ hastanın enjeksiyonları daha fazla yapmak istememesi nedeniyle, 6 hastada $(\% 5,6)$ MR aktivitesinde artış nedeniyle oral tedavi tercih edildi. En fazla atak sıklığında artış nedeniyle oral tedavi tercih edildiği saptandı (Şekil 2). Fingolimod kullananların ortalama EDSS'si $2,81 \pm 1,14$, ortalama hastalık süresi $11,11 \pm 6,67$ yıldı ve ortalama $21,67 \pm 19,72$ aydır bu tedaviyi kullanmaktaydılar. Dimetilfumarat kullananların ortalama EDSS'si 2,51 $\pm 1,36$, ortalama 
hastalık süresi $10,06 \pm 7,91$ yıldı ve ortalama $13,4 \pm 10,2$ aydır bu tedaviyi kullanmaktaydılar. Teriflunomid kullananların ise ortalama EDSS'si $1,42 \pm 0,69$, ortalama hastalık süresi $8,20 \pm 7,02$ yıldı ve ortalama $13,52 \pm 11,37$ aydır bu tedaviyi kullanmaktaydılar (Tablo 1). İlk basamak tedavi olarak; fingolimod sadece 4 hastaya (\%3), dimetilfumarat 7 hastaya (\%6), teriflunomid 5 hastaya (\%4) başlanmıştı. Her 3 grup değerlendirildiğinde en sık Interferon beta-1a 44 microgram'dan oral tedaviye geçiş gözlenmişti (fingolimoda geçiş \%30,2, dimetilfumarata geçiş $\% 29,4$, teriflunomide geçiş \%28,6).

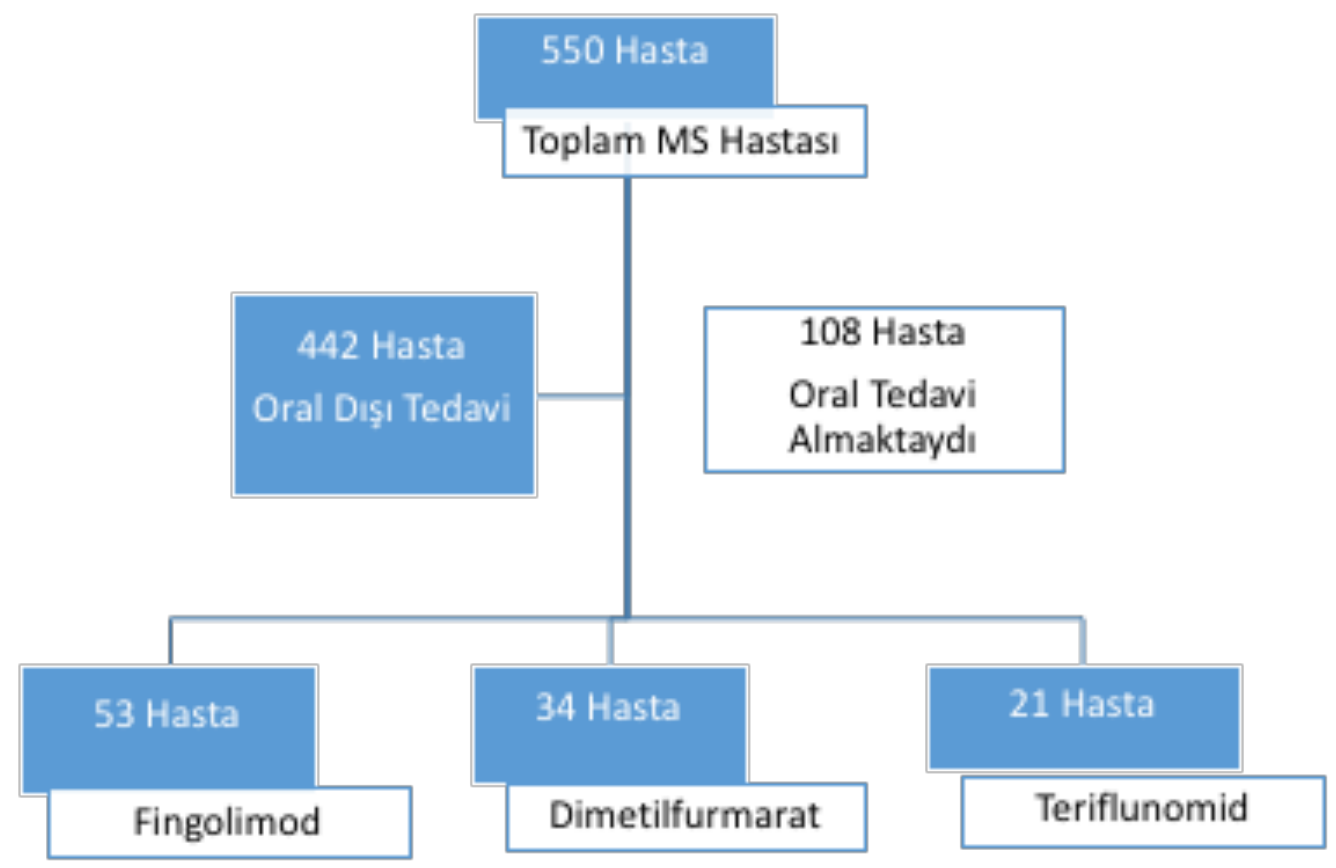

Şekil 1. Çalışmaya alınan hastaların kullanmakta oldukları tedaviler.

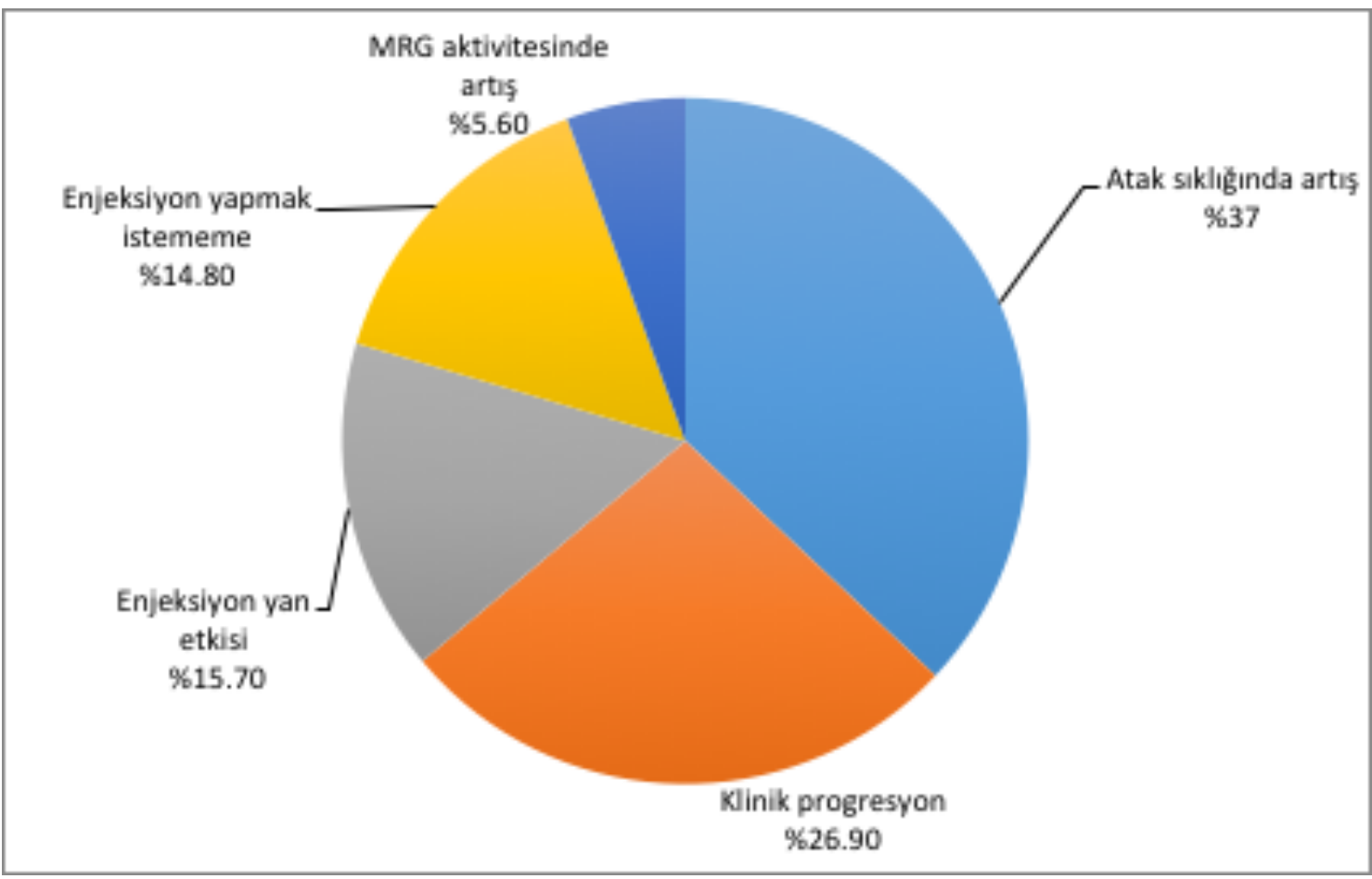

Şekil 2. Oral tedavi tercih edilme nedenleri. 
Tablo 1. Oral tedavi alan hastaların EDSS, ortalama hastalık süresi ve oral tedavi kullanım süreleri.

\begin{tabular}{llll}
\hline Oral tedavi & EDSS & $\begin{array}{l}\text { Ortalama Hastalık Süresi } \\
(\mathrm{y} \text { ıl })\end{array}$ & Ortalama Oral Tedavi Süresi (ay) \\
\hline Fingolimod & $2,81 \pm 1,14$ & $11,11 \pm 6,67$ & $21,67 \pm 19,72$ \\
Dimetilfumarat & $2,51 \pm 1,36$ & $10,06 \pm 7,91$ & $13,4 \pm 10,2$ \\
Teriflunomid & $1,42 \pm 0,69$ & $8,20 \pm 7,02$ & $13,52 \pm 11,37$ \\
\hline
\end{tabular}

\section{Tartışma}

Multipl skleroz, 18-60 yaş arasında en sık özürlülüğe neden olan hastalıktır. Tedavinin amacı en başta kalıcı nörolojik hasarı önlemek ya da geciktirmek, erken HMT ile hem yeni atak gelişmesi hem de sakatlığın ilerlemesini önlemektir [11, 12]. MS patogenezi fokal enflamatuar demyelinizasyon ve dejenerasyonu içeren iki komponentten oluşmaktadır. RRMS tedavisinde erken hastalık modifiye edici tedaviyi başlamanın amacı özellikle hastalığın enflamatuar fazını etkilemektir. Çünkü dejeneratif süreç başladığında bu tedavilerin etkisi azalmaktadır [13, 14]. Epidemiyolojik ve klinik çalışmalara göre optimal tedavi penceresinin hastanın EDSS'si 3'e ulaştığında kapandığı saptanmıştır [15-17]. Bu aşamadan sonra artık hastalık süreci inflamasyondan çok dejenerasyon yönüne kaymaktadır. Bizim hastalarımızda da tedavi değişiminde sebep ne olursa olsun bütün oral tedavi gruplarında ortalama EDSS'yi <3 olarak saptadık. Bu da bizim literatürle uyumlu olarak optimal tedavi penceresi içinde kaldığımızı göstermektedir.

Enjektabl ajanlara kıyasla oral ajanlar hastaların yaşam kalitesini ve tedavi uyumu artırmaktadır. Tedavi kararını verirken birçok faktör göz önünde bulundurulmalıdır. Hastalık aktivitesi, ataklar, nörolojik tablo, MR'daki lezyon yükü ve kontrast tutan beyin ve spinal kord lezyonları, anti-JCV pozitifliği, ilaca ulaşılabilirlik ve maliyet, hasta tercihi (gebelik planı, enjeksiyondan kaçınma veya yan etkiler) gibi faktörler bu kararı etkiler. Bir çalışmada, ciddi yan etkilerin ve tedavi etkinliğinin MS hastalarının HMT seçimini etkileyebileceği saptanmıştır. Bu nedenle hastaya özgü riskyarar değerlendirmesini yaparak bu karar verilmelidir [18]. Son 20 yılda MS tedavisi oldukça gelişmekte ve tedavi seçenekleri gün geçtikçe artmaktadır [19]. Bu durum hem hastaların hem de hekimlerin tedavi seçimini zorlaştırmakta ancak artan oranda da atak ve sakatlığın önüne geçilebilmektedir [20]. Bu nedenle tedavinin uygunluğu aynı zamanda hastanın tedaviye uyumunu da sağlamakta ve başarılı bir tedavi için kritik rol oynamaktadır [21-23].

2010 yılında Amerika Birleşik Devletleri (ABD)'nde, 2011'de ise Avrupa Birliği (AB)'nde ilk oral hastalık modifiye edici ilaç olan fingolimod kullanılmaya başlandı ve bunu teriflunomid ve dimetil fumarat takip etti. Ülkemizde ise sırasıyla 2011 ve sonrasında bu tedaviler ruhsatlandırıldı. Halen, Fingolimod 2.basamak, teriflunomid ve dimetilfumarat 1.basamak tedavi olarak kullanılmaktadır. Bizim çalışmamızda oral tedavi kullanan hastalarımızın yaklaşık yarısı $(\% 49,1)$ fingolimod kullanmaktaydı ve diğerleri ile karşılaştırıldığında en fazla kullanım süresi olan, ortalama EDSS'si daha yüksek olan hasta grubunda kullanılan da bu ilaçtı. Bu durum fingolimodun diğerlerinden daha önce ruhsatlandırılmasıyla ve ikinci basamaktaki etkin bir tedavi olmasıyla ilişkili olabilir.

Fingolimod ile interferon beta-1a (INF $\beta$ 1a) intramuskuler (im)'in karşılaştırıldığı 12 aylık faz 3 pivotal çalışmada (TRANSFORMS), fingolimod 0,5 veya $1,25 \mathrm{mg}$ kullanan hasta kollarının INF $\beta$-1a koluna göre relaps hızında azalmada ve relapsa kadar geçen sürede uzamada üstünlük gösterdiği saptanmıştır [24]. Bu çalışmanın 1 yıl uzatma çalışmasında, INF $\beta$ 1a im'den fingolimod 0,5 veya 1,25 mg'a geçen kollarda ilk çalışmaya göre yıllık relaps hızında azalma saptanmış ve fingolimodun ek klinik yarar sağladığı gösterilmiştir [25].

Fingolimodun plaseboya göre karşılaştırıldığı FREEDOMS çalışmasında da fingolimod alan grupta klinik ve MR sonuçlarında iyileşme ve sakatlığın ilerlemesinde azalma saptanmıştır [26]. FREEDOMS II çalışmasında ise farklı olarak sakatlığın ilerlemesinde istatistiksel 
anlamlı fark saptanmamıştır. Yan etki olarak, plasebo koluna göre fingolimod kullananlarda herpes zoster, alt solunum yolu ve influenza enfeksiyonlarında artış görülmüştür. Makuler ödem fingolimod kolunda daha sık, hipertansiyon diğer çalışmalara göre biraz daha sık görülmekle birlikte hasta grubunun tedaviye başlamadan önce hipertansiyonu olması ve vücut kitle indekslerinin daha yüksek olmasına bağlanmıştır. Deri maligniteleri fingolimod ve plasebo kolunda benzer bulunmuştur [27]. Ancak TRANSFORMS çalışmasında fingolimod $1,25 \mathrm{mg}$ ile tedavi edilen grupta 2 hastadan birinde herpes simpleks ensefaliti diğerinde disemine varicella zoster enfeksiyonu sonucu ölüm görülmüştür. Bu çalışmalarda fingolimod alanlarda varicella zoster enfeksiyonlarında artış görülmüş olup FREEDOMS II çalışmasında daha önce immunsupresif almayan 3 hastada ve daha önce natalizumab tedavisi alan 17 hastada PML saptanmıştır [20].

Dimetilfumaratın ise iki plasebo kontrollü faz 3 çalışmasında (DEFINE ve CONFIRM), aynı zamanda CONFIRM'de glatiramer asetat ile karşılaştırmasında, kabul edilebilir bir güvenlik profiliyle birlikte klinik ve nöroradyolojik etkililik görülmüştür. Yeni atak gelişimi, sakatlığın ilerlemesi ve beyin MR lezyonlarında azalma saptanmıştır. En sık görülen yan etkiler; flushing ve diare olarak saptanmış olup enfeksiyon ve malignensi insidansı plasebo ile benzer bulunmuştur. Lökosit ve lenfosit sayılarında \%10-30 kadar düşüş ilk yılda gözlenmiş, sonra plato çizmiş, karaciğer enzimlerinde de 3 katı geçmeyen artışlar görülmüştür. Uzatma çalışması ENDORSE'da ise uzamış lenfopenisi olanlardan biri fatal olmak üzere 3 hastada PML görülmüştür [28, 29].

Teriflunomidin de etkinliği üç plasebo kontrollü faz 3 çalışmasıyla (TEMSO, TOWER, TOPIC) ve bir interferon beta 1a (INF $\beta-1 a)$ ile karşılaştırmalı çalışmasında (TENERE) gösterilmiştir [30-33].Yan etki olarak $\geq \% 10$ hastada diare, bulantı, ALT yüksekliği ve saçlarda incelme saptanmıştır. Plaseboya kıyasla ciddi enfeksiyon riskinde artış saptanmamış ancak polinöropati daha sık gözlenmiş ve sistolikdiastolik kan basınçlarında yükselme ile lökosit sayılarında ılımlı düşüş görülmüştür. Hayvan çalışmalarında teratojenite ve embriyo ölümü nedeniyle de gebelikte kullanımı kontrendike olarak bildirilmiştir. Teriflunomid vücuttan atılımı çok yavaş olduğundan plazmadan temizlenmesi yaklaşık 2 yılı bulur. Hızlandırılmış atılımla teriflunomidin intestinal seviyede geri emilimi önlenmiş olur. Hızlandırılmış atılım için kolestiramin $8 \mathrm{~g}$, günde $3 \mathrm{kez}, 11$ gün boyunca kullanılmalıdır [34].

Sonuç olarak her 3 oral ajanın da Faz III çalışmalarında plaseboyla karşılaştırıldığında atak hızında azalmaya neden olduğu görülmüştür. Fingolimodun diğer 2 oral ajana kıyasla RRMS tedavisinde daha yüksek etkinliğe sahip olduğu aynı zamanda daha fazla güvenlik problemine yol açtığı saptanmıştır.

2016'da yapılan 128 hastalık bir Brezilya çalışmasında, hastaların \%72,7'sinde tedavi interferonlar (IFN $\beta-1 b$, IFN $\beta-1 a$ im, IFN $\beta-1 a$ sc), glatiramer asetat ya da natalizumabtan fingolimoda değiştirilmiş ve hastaların \%90'ının bu tedaviden memnun olduğu saptanmıştır [35]. Ancak yine de önceliğimiz hastanın güvenliği olmalıdır ve hastanın klinik durumuna göre karar verilmelidir. Yüksek hastalık aktivitesi olan hastalarda bu durum değişebilir ve etkililik güvenlikten daha ön plana geçebilir. Bizim hastalarımızda enjeksiyon tedavilerinden en sık interferon beta-1a 44 microgram'dan oral tedavilere benzer oranlarda geçiş sağlanmıştır. $\mathrm{Bu}$ durumun, hastalık aktivitesi yüksek olan hastalarda interferon beta-1a 44 microgram başlama tercihinin daha fazla olması ve bu tedavi ile hastalık aktivitesi artanlarda çoğunlukla fingolimod ve dimetilfumarat gibi daha etkili olduğu gösterilen yeni tedavilere geçilmesine bağlı olduğu düşünülmüştür. Teriflunamid kullanan hastalarda ise çoğunlukla enjeksiyona bağlı yan etkiler nedeni ile veya hastaların oral ilaç tercih etmesi nedeni ile ilaç değişimi yapıldığı görüldü.

Türkiye'de ve dünyada 2018 verilerine göre oral tedavi kullanım oranı \%41 civarında olduğu tahmin edilmekte olup bizim oral tedavi deneyimimizde bu oran \%19,6 bulunmuştur. $\mathrm{Bu}$ düşüklüğün sebebi hastaların yıllardır kullanmakta olduğu ilaçları zorunlu olmadıkça kesmek istememesi, oral ilaçların yan etki profilleri nedeniyle hastaların çekimser kalması, EDSS ortalamasının nispeten düşük olması nedeniyle hemen bir üst basamak tedaviye geçişin düşünülmemesidir. Biz hekimlerin ise daha konservatif yaklaşarak yirmi yıldan fazladır birinci basamakta kullanılmakta olan enjeksiyon tedavilerinin güvenlik profillerinin oral ilaçlara 
göre daha iyi olduğunu bilmemiz sonucu özellikle kullandığı tedavi ile atağı olmayan ve yeni MR lezyonu olmayıp stabil giden hastalarda tedavi değişimi yapmayıp daha güvenli olduğu bilinen interferonlar ve glatiramer asetat gibi kullandığı tedavilere devam etmeyi seçmemiz sayılabilir. Dünyada ve Türkiye'de daha fazla hasta sayısına ulaşılarak tedavi deneyimi arttıkça bu oran büyük ölçüde değişecektir.

Çıkar İlişkisi: Yazarlar çıkar ilişkisi olmadığını beyan eder.

\section{Kaynaklar}

1. Pantazou V, Schluep M, Du Pasquier R. Environmental factors in multiple sclerosis. Presse Med 2015;44:e113120. http://dx.doi.org/10.1016/ j.lpm.2015.01.001

2. Wingerchuk DM, Weinshenker BG. Disease modifying therapies for relapsing multiple sclerosis. BMJ 2016;354:i3518. https://dx.doi.org/10.1136/bmj.i3518

3. Mulero P, Midaglia L, Montalban X. Ocrelizumab: a new milestone in multiple sclerosis therapy. Ther Adv Neurol Disord 2018;11:1-6. https://dx.doi. org/10.1177/1756286418773025

4. The use of disease-modifying therapies in multiple sclerosis: principles and current evidence. Summary, MS Coalition 2015. http://ms-coalition.org/cms/images/ stories/DMTfullpaper_2015update_final. pdf.

5. Berger JR, Fox RJ. Reassessing the risk of natalizumabassociated PML. J Neurovirol 2016;22:533-535. https:// dx.doi.org/10.1007/s13365-016-0427-6

6. Arvin AM, Wolinsky JS, Kappos L, et al. Varicella-zoster virus infections in patients treated with fingolimod: risk assessment and consensus recommendations for management. JAMA Neurol 2015;72:31-39. https:// dx.doi.org/10.1001/jamaneurol.2014.3065

7. Gold R, Arnold DR, Bar-Or A, et al. Long-term effects of delayed-release dimethyl fumarate in multiple sclerosis: interim analysis of ENDORSE, a randomized extension study. Mult Scler 2017;23:253-265. https:// dx.doi.org/10.1177/1352458516649037

8. Jeffery D, Bashir K, Buchwald L, et al. Optimizing immunomodulatory therapy for MS patients: an integrated management model. J Neurol Sci 2002;201:89-90.

9. Freedman M, Selchen D, Arnold D, et al. Treatment optimization in MS: Canadian MS Working Group updated recommendations. Can J Neurol Sci 2013;40:307-323.

10. Smith AL, Cohen JA, Hua LH. Therapeutic targets for multiple sclerosis: current treatment goals and future directions. Neurotherapeutics 2017;14:952-960. https://dx.doi.org/10.1007/s13311-017-0548-5
11. Bates D. Treatment effects of immunomodulatory therapies at different stages of multiple sclerosis in short-term trials. Neurology 2011;76:14-25. https:// dx.doi.org/10.1212/WNL.0b013e3182050388

12. Lublin FD, Baier M, Cutter G. Effect of relapses on development of residual deficit in multiple sclerosis. Neurology 2003;61:1528-1532.

13. Comi G, Radaelli M, Soelberg Sorensen P. Evolving concepts in the treatment of relapsing multiple sclerosis. Lancet 2017;389:1347-1356. https://dx.doi. org/10.1016/S0140-6736(16)32388-1

14. Bruck W, Stadelmann C. Inflammation and degeneration in multiple sclerosis. Neurol Sci 2003:24:265-267. https://dx.doi.org/10.1007/s10072-003-0170-7

15. Leray E, Yaouanq J, Le Page E, et al. Evidence for a two-stage disability progression in multiple sclerosis. Brain 2010;133:1900-1913. https://dx.doi.org/10.1093/ brain/awq076

16. Confavreux C, Vukusic S, Adeleine P. Early clinical predictors and progression of irreversible disability in multiple sclerosis: an amnesic process. Brain 2003;126:770-782.

17. Freedman MS. Multiple sclerosis therapeutic strategies: use second-line agents as first-line agents when time is of the essence. Neurol Clin Pract 2011;1:66-68. https:// dx.doi.org/10.1212/CPJ.0b013e31823cc2c2

18. Johnson F, Van Houtven G, Ozdemir S, et al. Multiple sclerosis patients' benefit-risk preferences: serious adverse event risks versus treatment efficacy. J Neurol 2009;256:554-562. https://dx.doi.org/10.1007/s00415009-0084-2

19. Linker R, Kieseier B, Gold R. Identification and development of new therapeutics for multiple sclerosis. Trends Pharmacol Sci 2008;29:558-565. https://dx.doi. org/10.1016/j.tips.2008.07.012

20. Guarnera C, Bramanti P, Mazzon E. Comparison of efficacy and safety of oral agents for the treatment of relapsing-remitting multiple sclerosis. Drug Des Devel Ther 2017;11:2193-2207. https://dx.doi.org/10.2147/ DDDT.S137572

21. Prosser LA, Kuntz KM, Bar-Or A, Weinstein MC. Patient and community preferences for treatments and health states in multiple sclerosis. Mult Scler 2003;9:311-319. https://dx.doi.org/10.1191/1352458503ms903oa

22. Killestein J, Rudick R, Polman C. Oral treatment for multiple sclerosis. Lancet Neurol 2011;10:1026-1034. https://dx.doi.org/10.1016/S1474-4422(11)70228-9

23. Patti F. Optimizing the benefit of multiple sclerosis therapy: the importance of treatment adherence. Patient Prefer Adher 2010;4:1-9.

24. Cohen JA, Barkhof F, Comi G, et al. Oral fingolimod or intramuscular interferon for relapsing multiple sclerosis. N Engl J Med 2010;362:402-415. https:// dx.doi.org/10.1056/NEJMoa0907839 
25. Khatri B, Barkhof F, Comi G, et al. Comparison of fingolimod with interferon beta-1a in relapsingremitting multiple sclerosis: a randomised extension of the TRANSFORMS study. Lancet Neurol 2011;10:520529. https://dx.doi.org/10.1016/S1474-4422(11)700990

26. Kappos L, Radue EW, O'Connor P, et al. A placebocontrolled trial of oral fingolimod in relapsing multiple sclerosis. N Engl J Med 2010;362:387-401. https:// dx.doi.org/10.1056/NEJMoa0909494

27. Calabresi PA, Radue EW, Goodin D, et al. Safety and efficacy of fingolimod in patients with relapsing-remitting multiple sclerosis (FREEDOMS II): a double-blind, randomised, placebo-controlled, phase 3 trial. Lancet Neurol 2014;13:545-556. https://dx.doi.org/10.1016/ S1474-4422(14)70049-3

28. Gold R, Kappos L, Arnold D, et al. Placebo-controlled Phase 3 BG-12 for relapsing multiple sclerosis. N Engl J Med 2012;367:1098-1107. https://dx.doi.org/10.1056/ NEJMoa1114287

29. Fox RJ, Miller DH, Phillips JT, et al. Placebo-controlled phase 3 study of oral BG-12 or glatiramer in multiple sclerosis. N Engl J Med 2012;367:1087-1097. https:// dx.doi.org/10.1056/NEJMoa1206328

30. O'Connor P, Wolinsky JS, Confavreux C, Comi G, Kappos L, Olsson TP. et al. Randomized trial of oral teriflunomide for relapsing multiple sclerosis. N Engl J Med 2011;365:1293-1303. https://dx.doi.org/10.1056/ NEJMoa1014656

31. Confavreux C, O'Connor P, Comi G, et al. Oral teriflunomide for patients with relapsing multiple sclerosis (TOWER): a randomised, double-blind, placebo-controlled, phase 3 trial. Lancet Neurol 2014;13:247-256. https://dx.doi.org/10.1016/S14744422(13)70308-9

32. MillerAE, Wolinsky JS, Kappos L, et al. Oral teriflunomide for patients with a first clinical episode suggestive of multiple sclerosis (TOPIC): a randomised, doubleblind, placebo-controlled, phase 3 trial. Lancet Neurol. 2014;13:977-986. https://dx.doi.org/10.1016/S14744422(14)70191-7

33. Vermersch P, Czlonkowska A, Grimaldi LM, et al. Teriflunomide versus subcutaneous interferon beta-1ain patients with relapsing multiple sclerosis: a randomised, controlled phase 3 trial. Mult Scler. 2014;20:705-716. https://dx.doi.org/10.1177/1352458513507821

34. European Medicines Agency. Aubagio EU summary of product characteristics. 2014. http://www.ema.europa. eu/docs/en GB/ document library/EPAR Product Information/human/002514/WC500148682.pdf. Accessed 20 May 2015.

35. Spessotto CV, Cavalli H, Eboni AC, et al. Patients' satisfaction with and views about treatment with disease-modifying drugs in multiple sclerosis. Arq Neuropsiquiatr 2016;74:617-620. https://dx.doi. org/10.1590/0004-282×20160091
Yazarlar Sayın Doç.Dr. Aysun Soysal'a katkılarından dolayı teşekkür eder. 